\title{
JANUS 11 (2022) 81-85
}

ISSN 2254-7290

\section{Reseña de: Felipe B. Pedraza, El Arte nuevo de hacer comedias de Lope de Vega: contexto y texto, New York, Instituto de Estudios Auriseculares (IDEA), 2020. ISBN: 978-1-938795-63-3}

\author{
Iván Gómez Caballero \\ <ORCID: https://orcid.org/0000-0001-8792-1088> \\ Universidad de Castilla-La Mancha (España) \\ ivangomezcaballero29@gmail.com
}

JANUS 11 (2022)

Fecha recepción: 10/12/21, Fecha de publicación: 12/01/2022

<URL: https://www.janusdigital.es/articulo.htm?id=202>

$<$ DOI: https://doi.org/10.51472/JESO20221103>

\section{Resumen}

Reseña del volumen que reúne varios artículos del autor que pretenden trazar el contexto en que nació el discurso Arte nuevo de hacer comedias, de Lope de Vega; su origen y significado, el marco académico en que se gestó, sus vicisitudes editoriales, el preciso alcance de su título, sus relaciones con otras obras del autor, etc. Sigue una edición del texto, críticamente editado, con las variantes de todos los testimonios de relieve.

\section{Palabras clave}

Lope de Vega; Arte nuevo de hacer comedias, teatro español del Siglo de Oro

\section{Title}

Review of: Felipe B. Pedraza, El Arte nuevo de hacer comedias de Lope de Vega: contexto y texto, New York, Instituto de Estudios Auriseculares (IDEA), 2020. ISBN: 978-1-938795-63-3.

\footnotetext{
Abstract

Review of the volume that brings together several articles by the author that seek to trace the context in which the discourse Arte nuevo de doing comedias, by Lope de Vega, was born; its origin and meaning, the academic framework in which it was
} 
conceived, its editorial vicissitudes, the precise scope of its title, its relationships with other works by the author, etc. The book also includes a critical edition of the text, pointing out the variants of all the preserved testimonies.

\section{Keywords}

Lope de Vega; Arte nuevo de hacer comedias, Spanish Theatre $17^{\text {th }}$ Century
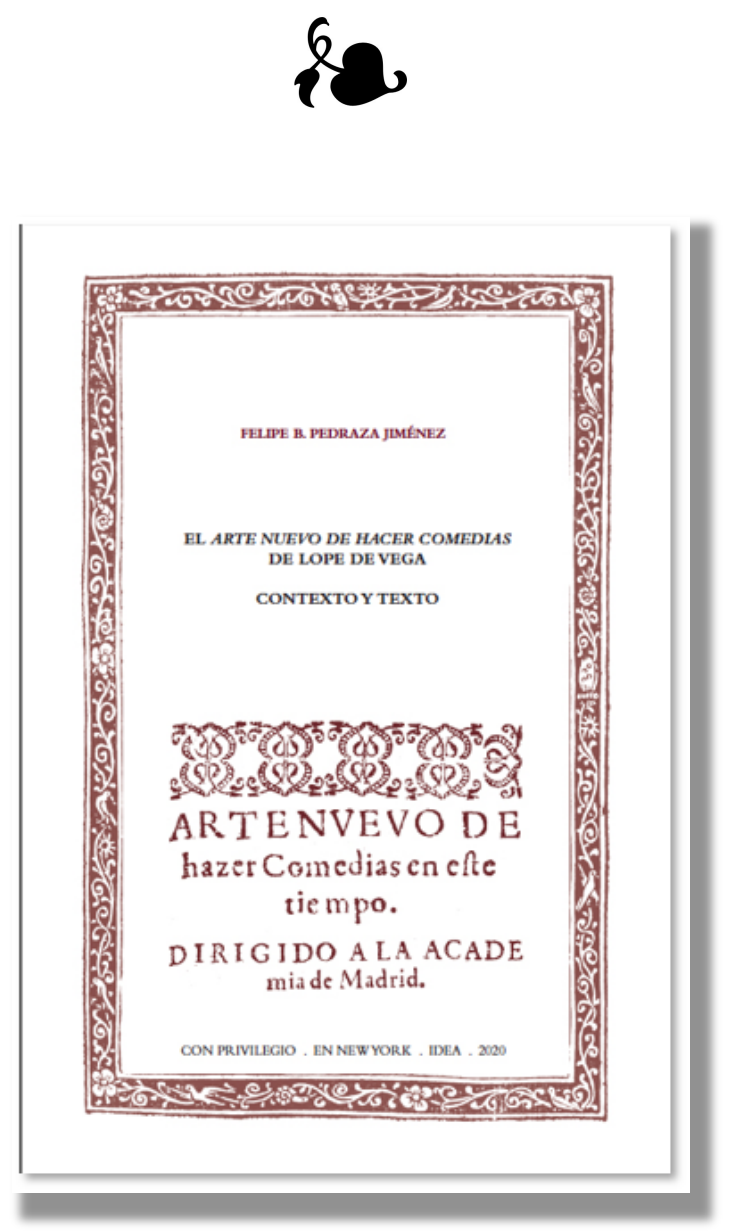

El lopista Felipe B. Pedraza Jiménez, catedrático de Literatura Española en la Universidad de Castilla - La Mancha, reúne los artículos de revista y capítulos de libros que ha publicado sobre El arte nuevo de hacer comedias en este tiempo, al igual que en La fuerza del amor y de la historia: ensayos 
sobre el teatro de Lope de Vega ${ }^{1}$, en donde recoge en forma de libro sus múltiples artículos sobre el teatro de Lope. Esta monografía aborda dos grandes bloques temáticos: por un lado, el contexto donde estudia su relación con tratados de teoría literaria, junto con su origen, con su género y con el teatro español del siglo XVII, y, por otra parte, realiza un estudio de ecdótica textual en donde fija el texto. Estos trabajos de Felipe B. Pedraza se financiaron con dos proyectos subvencionados por el Ministerio de Ciencia e Innovación: uno dirigido por él mismo y otro por Joan Oleza, catedrático de la Universidad de Valencia.

La primera parte de la obra, en la que se estudia el contexto, se divide en varios capítulos: «El Arte nuevo de hacer comedias y la cristalización del teatro moderno» (pp. 19 - 34), «Arte nuevo, un rótulo polémico ¿y paradójico» (pp. 35 - 50), «Precisiones sobre el Arte nuevo: la academia del conde de Saldaña» (pp. 51 - 68), «El Arte nuevo de hacer comedias en las Rimas» (pp. 69 - 74), «El Arte nuevo de hacer comedias: origen y género» (pp. 95 - 104), «Lope de Vega: escritos sobre el teatro. Del poeta al lector» (pp. 105 - 122) y, por último, «Entre centenarios: el Arte nuevo de hacer comedias y Darwin» (pp. 123 - 130). Por otro lado, en la segunda parte encontramos un capítulo sobre «Cuestiones ecdóticas» (pp. 133 - 144) y también el texto fijado, «Arte nuevo de hacer comedias en este tiempo» (pp. 145 - 162).

En el prólogo de la obra, establece un status quaestionis del Arte nuevo desde el año 2009, aportando valiosa información sobre los congresos y espectáculos que se han celebrado, junto con ediciones, traducciones, números monográficos de revistas, actas de congresos y libros monográficos que se han publicado. El primer capítulo, «El Arte nuevo de hacer comedias y la cristalización del teatro moderno» (pp. $19-34)$, se centra en el estudio de la impresión del Arte nuevo... por parte de Francisco de Murcia de la Llana en 1609, que contenía varios errores tipográficos que Lope de Vega tuvo que corregir en una $\mathrm{Fe}$ de erratas. Así, Felipe B. Pedraza considera que después de 1608 Lope quiso incorporar varios poemas al libro que acababa de publicar, pues Arte nuevo... acaba con un rótulo curioso ( $(F i n$ de las Rimas»), junto con la información contenida en el rótulo general. Para el investigador, el Arte nuevo... es un texto crucial en la literatura española en tanto que anuncia la aparición de un teatro moderno en Europa, al que, curiosamente, asistirá un público masivo, a diferencia de otras épocas literarias. Nace, por ende, un teatro que se basa en las leyes económicas de la

${ }^{1}$ Felipe B. Pedraza Jiménez, La fuerza del amor y de la historia: ensayos sobre el teatro de Lope de Vega, Cuenca, Servicio de Publicaciones de la Universidad de Castilla-La Mancha, 2018. 
oferta y la demanda, por lo que, si el autor juega bien sus cartas, podrá ganar mucho dinero.

En el segundo capítulo, «Arte nuevo, un rótulo polémico ¿y paradójico» (pp. 35 - 50) se analiza el título de la obra, pues ha sembrado varias polémicas entre los filólogos hispánicos, especialmente en los investigadores auriseculares y los lopistas. Según Felipe B. Pedraza, el Arte nuevo de hacer comedias en este tiempo se contrapone claramente a los

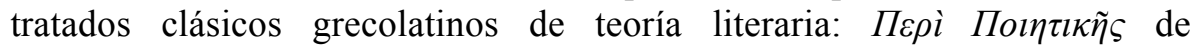
Aristóteles y Epistula ad Pisones de Horacio, aunque también hay en el título cierta reminiscencia del Ars poetica de Quintiliano. En los tratados coetáneos y próximos a Lope, fue muy habitual titular como "arte" los tratados literarios, pues así lo hicieron Francesco Robortelli, Bartolomeo Lombardi, Pietro Vittorio y Bernardo Segni, entre otros. El adjetivo "nuevo" se refiere a que es un tratado de teoría literaria moderno, en contraposición a la larga tradición que habían disfrutado las preceptivas aristotélicas. Es plausible, además, que Lope conociera El arte nuevo de contar... (1599) de Ignacio Pérez y se inspirara en el título.

Felipe B. Pedraza quiere desmentir la influencia del conde de Saldaña en el Arte nuevo, cuyo vínculo, se debe a la Academia literaria de Madrid, en «Precisiones sobre el Arte nuevo: la academia del conde de Saldaña» (pp. 51 - 68). Sin embargo, Pedraza no cree que la Academia de Madrid y la Academia de Saldaña sean la misma, sino que deberían ser dos diferentes. No obstante, hay ciertos detractores de esta hipótesis que han considerado que es la misma. En el cuarto capítulo, «El Arte nuevo de hacer comedias en las Rimas» (pp. 69 - 74), explica la transmisión textual de las Rimas, que se publicaron en varias ediciones ya en el siglo XVII, y las relaciones literarias con el Arte nuevo..., pues se publicó en 1609, aunque tenemos que recordar que las Rimas son anteriores. Concluye que «el Arte nuevo venía a rematar, a completar, el proyecto creativo de las Rimas» (p. 75). El éxito editorial de esta obra fue mucho mayor que el resto y puede equipararse con el Quijote de 1605. De esta forma, en vida de Lope se publicaron un total de diez ediciones de las Rimas.

En el capítulo «El Arte nuevo de hacer comedias: origen y género» (pp. 95 - 104), analiza la estructura del Arte nuevo de hacer comedias, relacionándolo también con los tratados teóricos de Aristóteles y Horacio. Asimismo, se centra también en «Lope de Vega: escritos sobre el teatro. Del poeta al lector» (pp. $105-122$ ) en el estudio de algunos textos de Lope de Vega que tocan cuestiones de teoría literaria, además de, obviamente, el Arte nuevo..., hay que destacar algunas piezas teatrales como Lo fingido verdadero, junto con las dedicatorias de las comedias, los prólogos de las Partes y algunas de sus epístolas horacianas. Es frecuente encontrar 
reflexiones sobre la configuración de los personajes, las fuentes, los derechos de autor, los memorillas y las dificultades económicas como consecuencia del encarecimiento de los alquileres de los corrales de comedias, entre otros aspectos diversos.

Por último, el lopista castellanomanchego compara el Arte nuevo de hacer comedias en este tiempo con El origen de las especies por medio de la selección natural de Charles Darwin en «Entre centenarios: el Arte nuevo de hacer comedias y Darwin» (pp. 123 - 130), ya que anuncian un cambio de paradigma en el teatro español y en la ciencia, respectivamente. Ambas obras sorprendieron a los lectores de su tiempo y contaron, por supuesto, con detractores, al igual que con admiradores. Curiosamente, ambas obras se dirigen, no solo a los entendidos en la materia, sino al público en general; de ahí su triunfo y su pervivencia en el canon literario y científico. En «Cuestiones ecdóticas» (pp. 133 - 144), capítulo perteneciente al segundo bloque, estudia la transmisión del Arte nuevo... desde la crítica textual siguiendo el codex optimus de la edición de 1613. Sobre este texto lopesco, no se conservan manuscritos autógrafos, pero sí impresos apógrafos.

Este nuevo libro del catedrático y reputado lopista Pedraza Jiménez conforma, por un lado, un valioso conglomerado de estudios y, por otro, la edición crítica de Arte nuevo de hacer comedias de Lope de Vega.

En definitiva, encontrará el lector en El arte nuevo de hacer comedias de Lope de Vega: contexto y texto un estudio sugerente y refrescante sobre el contexto desde múltiples perspectivas como hemos visto: el origen, la datación, el género literario, el porqué del nombre del título, cuestiones ecdóticas, reflexiones metateatrales de Lope en sus obras literarias, las relaciones con las preceptivas aristotélicas y también con Horacio, junto con otros aspectos diversos. Así pues, la gran experiencia en crítica textual de Felipe B. Pedraza Jiménez hace que esta edición sea una de las mejores sobre el Arte nuevo... 